\title{
ALÍQUOTA ZERO EM RELAÇÃO AO PIS E A COFINS: UMA ANALISE DAS LEIS 9.317/96 E 10.147/2000
}

\author{
ZERO ALIQUOTE IN RELATION TO PIS AND COFINS:
}

AN ANALYSIS OF LAWS 9.317 / 96 AND 10.147 / 2000

\author{
Paulo Joviniano Alvares dos Prazeres* \\ Raymundo Juliano Rego Feitosa**
}

\begin{abstract}
RESUMO
A abordagem o estudo proposto visa destacar a problemática quando da ocorrência da dupla tributação nos tributos PIS e COFINS quando o sujeito passivo da obrigação são as microempresas e empresas de pequeno porte optantes do sistema de arrecadação única SIMPLES. Destaca-se que a dupla incidência tributaria é vetada por nosso ordenamento jurídico, analisando-se que a ocorrência de tal fato deve ser pelo Estado debelado.
\end{abstract}

Palavras-chaves: Alíquota Zero; Incidência Tributaria; SIMPLES; PIS; COFINS

\section{SUMMARY}

The approach proposed in this study aims to highlight the problem when double taxation occurs in the PIS and COFINS taxes when the taxable person is the microenterprises and small companies that opt for the SIMPLES single collection system. It should be noted that the double tax incidence is vetoed by our legal system, analyzing that the occurrence of this fact must be by the debelado State.

Keywords: Zero rate; Tax Incidence; SIMPLE; PIS; COFINS

\footnotetext{
* Doutorando em Direito Pela Universidade Católica de Pernambuco UNICAP; Doutorando em Ciências da Educação pela Universidad Autónoma de Asunción UAA; Doutorando em Direito e Ciências Sociais pela Universidad Nacional de Córdoba UNC; Mestrando em Ciências da Religião pela Faculdade UNIDA; Mestre em Direito pela Faculdade Damas da Instrução Crista FADIC; Mestre em Ciências da Educação pela Universidad Del Sol UNADES; Mestre em Direito das Relações Internacionais pela Universidad De la Empresa UDE; Graduado em Direito pela Universidade Católica de Pernambuco; Graduado UNICAP; Licenciado em Filosofia pela Faculdade Entre Rios do Piauí FAERPI; Graduado em Teologia pela Faculdade de Teologia Integrada FATIN; Graduado em Relações Internacionais pelo Centro Universitário Internacional UNINTER; Licenciado em Pedagogia pela faculdade Alfa América; Graduado em Ciências Contábeis pelo Centro Universitário Cidade Verde UNIFCV. paulojoviniano@ hotmail.com.

** Possui graduação em Direito pela Faculdade de Direito de Caruaru (1974), mestrado em Sociologia pela Universidade Federal de Pernambuco (1978) e doutorado em Direito - Universidad Autonoma de Madrid (1993). Pós-Doutorado na Universidad Castilla La Mancha (2005). Foi professor adjunto da Universidade do Estado do Amazonas - UEA ( docente no Programa de Pós-Graduação em Direito Ambiental e igualmente, foi professor adjunto da Universidade Federal de Pernambuco. Foi Coordenador do Programa de Pós-Graduação em Direito (Mestrado e Doutorado) da Universidade Federal de Pernambuco. É professor da Universidade Católica de Pernambuco - UNICAP (Mestrado em Direito), da Universidade Estadual da Paraíba (UEPB), e da ASCES. Tem experiência na área de Direito, com ênfase em Direito Tributário, atuando principalmente nos seguintes temas: federalismo, reforma tributária, sistemas tributários, tributação indutora e intervenção econômica. Professor Visitante nas Universidades de Salamanca e Castilla la Mancha na Espanha. Foi presidente do CONPEDI em três mandatos (2003/2005, 2005/2007, 2013/2015) e atual presidente (2015/2017). raymundojf@gmail.com.
} 


\section{INTRODUÇÃO}

Com o intuito de possibilitar às Microempresas e Empresas de Pequeno Porte maior competitividade no mercado interno, o Ente Federativo instituiu o Sistema Integrado de Pagamento de Impostos e Contribuições das Micro e Pequenas Empresas, denominado Simples, nos termos da Lei $\mathrm{N}^{0}$ 9.317, de 1996, tendo sofrido alterações posteriores, em cumprimento ao disposto no art. 179 da Constituição Federal de 1988.

Assim, o Simples proporcionaria uma arrecadação unificada dos impostos, com o intuito de desburocratizar a arrecadação e facilitar a fiscalização dessas empresas optantes, que são os principais pilares da sustentação da economia nacional.

Com o advento da Lei 10.147/2000, que dispôs sobre a incidência monofásica para as contribuições do PIS e da COFINS, notadamente na tributação dos setores de combustíveis, veículos e medicamentos, o recolhimento dessas contribuições foi majorado e concentrado no início da cadeia produtiva, sendo suportada pelo produtor ou importador, que se responsabilizaria pela arrecadação de todo o seu setor. Em decorrência disso, foi reduzida a zero a alíquota das empresas que participam dessa cadeia, porém não enquadradas como industrial ou importador.

No entanto, inexplicavelmente, foram excluídas da redução a zero das alíquotas as empresas integrantes do ciclo econômico que tenham optado pelo SIMPLES, que já efetuaram o recolhimento das contribuições e demais tributos de forma unificada. No mesmo sentido, estes optantes não foram excluídos da sistemática monofásica, ocasionando, assim, a compra de produtos onerados pela alíquota majorada recolhida pelo importador e fabricante.

Logo, se constata das informações acima transcritas que os contribuintes revendedores que tenham optado pelo SIMPLES estão suportando uma dupla incidência de PIS e COFINS, já que recolhem a alíquota unificada do seu sistema próprio e suportam no preço de aquisição de produtos, a alíquota majorada recolhida pelo produtor ou importador, no início da cadeia econômica.

Impende ressaltar que a dupla incidência fere frontalmente os princípios da isonomia e da capacidade contributiva e aniquila a proteção ao desenvolvimento das Micro e Pequenas Empresas. 
Paulo Joviniano Alvares dos Prazeres \& Raymundo Juliano Rego Feitosa

Assim, o propósito inicial de possibilitar aos optantes do SIMPLES competitividade de mercado, cai por terra, já que terminam se submetendo a tratamento mais gravoso, pois recolhem em duplicidade as contribuições sociais, sendo-lhes negada a redução a zero do PIS e da COFINS, por imotivada discriminação na sistemática adotada pela Fazenda Pública.

Diante da problemática enfrentada pelas MPE, o presente estudo visa analisar a possível inconstitucionalidade da duplicidade da cobrança realizada no recolhimento de PIS e da COFINS, em relação às empresas optantes do SIMPLES, com destaque para as empresas do ramo farmacêutico.

\section{DO SIMPLES NACIONAL}

\subsection{Da instituição do Simples Nacional na legislação brasileira.}

Com a aprovação do Congresso Nacional, o Simples Nacional foi instituído pela Lei Complementar $n^{\circ}$ 123, de 14 de dezembro de 2006, em substituição ao Simples Federal, que era o anterior Regime tributário de Microempresas e Empresas de Pequeno Porte, que previa a instituição de um Sistema Integrado de Pagamento de Impostos e Contribuições, com base no disposto nos artigos 170 e 179 da Constituição Federal.

A nossa Carta Magna já previa em capítulo voltado para os aspectos da ordem econômica, a instituição de um regime simplificado de obrigações tributárias, administrativas, previdenciárias e creditícias, com o fim de incentivar as micro e pequenas empresas, a ter um tratamento diferenciado, simplificado e favorecido ${ }^{1}$.

Como a previsão constitucional prevê a regulamentação deste regime por lei, foi publicado em 06 de dezembro de 1996 o regime tributário das microempresas e empresas de pequeno porte, com o fim de instituir este Sistema Integrado de Pagamento de Impostos e Contribuições.

1 Art. 179 da CRFB/88 - A União, os Estados, o Distrito Federal e os Municípios dispensarão às microempresas e às empresas de pequeno porte, assim definidas em lei, tratamento jurídico diferenciado, visando a incentivá-las pela simplificação de suas obrigações administrativas, tributárias, previdenciárias e creditícias, ou pela eliminação ou redução destas por meio de lei. 
Em julho de 2006 esta lei foi revogada pela atual Lei Complementar ${ }^{\circ} 123$ de 2006, que prevê as normas gerais do Estatuto Nacional das Microempresas e Empresas de Pequeno Porte, a fim de garantir a estas empresas competitividade no mercado.

Assim, diante da necessidade de desburocratização da atividade econômica das empresas e da necessidade de aumento de produção, com consequente criação de novos empregos nos Estados, foi instituído este Sistema, voltado para estas empresas que possuem grande relevância para o país, em razão de serem responsáveis pela maioria absoluta dos negócios.

\subsection{Do Regime do Simples Nacional}

Para administração desse regime foi criado um Comitê de Gestão, formado por oito membros, dos quais quatro são integrantes da Secretaria da Receita Federal do Brasil, com poder representativo da União, dois são integrantes dos Estados e Distrito Federal e dois são integrantes dos Municípios, conforme disposto no artigo $2^{\circ}$, inciso I, da legislação específica $^{2}$.

2 Art. $2^{\mathbf{o}} \mathrm{O}$ tratamento diferenciado e favorecido a ser dispensado às microempresas e empresas de pequeno porte de que trata $\mathrm{o}$ art. $1^{\circ}$ desta Lei Complementar será gerido pelas instâncias a seguir especificadas:

I - Comitê Gestor do Simples Nacional, vinculado ao Ministério da Fazenda, composto por 4 (quatro) representantes da Secretaria da Receita Federal do Brasil, como representantes da União, 2 (dois) dos Estados e do Distrito Federal e 2 (dois) dos Municípios, para tratar dos aspectos tributários; e

II - Fórum Permanente das Microempresas e Empresas de Pequeno Porte, com a participação dos órgãos federais competentes e das entidades vinculadas ao setor, para tratar dos demais aspectos, ressalvado o disposto no inciso III do caput deste artigo;

III - Comitê para Gestão da Rede Nacional para a Simplificação do Registro e da Legalização de Empresas e Negócios, vinculado ao Ministério do Desenvolvimento, Indústria e Comércio Exterior, composto por representantes da União, dos Estados e do Distrito Federal, dos Municípios e demais órgãos de apoio e de registro empresarial, na forma definida pelo Poder Executivo, para tratar do processo de registro e de legalização de empresários e de pessoas jurídicas.

$\S 1^{\circ}$ Os Comitês de que tratam os incisos I e III do caput deste artigo serão presididos e coordenados por representantes da União.§ $2^{\circ}$ Os representantes dos Estados e do Distrito Federal nos Comitês referidos nos incisos I e III do caput deste artigo serão indicados pelo Conselho Nacional de Política Fazendária - CONFAZ e os dos Municípios serão indicados, um pela entidade representativa das Secretarias de Finanças das Capitais e outro pelas entidades de representação nacional dos Municípios brasileiros.

$\S 3^{\circ}$ As entidades de representação referidas no inciso III do caput e no $\S 2^{\circ}$ deste artigo serão aquelas regularmente constituídas há pelo menos 1 (um) ano antes da publicação desta Lei Complementar. resolução.

$\S 4^{\circ}$ Os Comitês de que tratam os incisos I e III do caput deste artigo elaborarão seus regimentos internos mediante

$\S 5^{\circ} \mathrm{O}$ Fórum referido no inciso II do caput deste artigo tem por finalidade orientar e assessorar a formulação e coordenação da política nacional de desenvolvimento das microempresas e empresas de pequeno porte, bem como acompanhar e avaliar a sua implantação, sendo presidido e coordenado pela Secretaria da Micro e Pequena Empresa da Presidência da República. (Redação dada pela Lei nº 12.792, de 28 de março de 2013)

$\S 6^{\circ}$ Ao Comitê de que trata o inciso I do caput deste artigo compete regulamentar a opção, exclusão, tributação, fiscalização, arrecadação, cobrança, dívida ativa, recolhimento e demais itens relativos ao regime de que trata o art. 12 desta Lei Complementar, observadas as demais disposições desta Lei Complementar.

$\S 7^{\circ}$ Ao Comitê de que trata o inciso III do caput deste artigo compete, na forma da lei, regulamentar a inscrição, cadastro, abertura, alvará, arquivamento, licenças, permissão, autorização, registros e demais itens relativos à abertura, legalização e funcionamento de empresários e de pessoas jurídicas de qualquer porte, atividade econômica ou composição societária. 
Impende ressaltar que a opção pelo regime do Simples é facultativa, e uma vez efetivada, a mesma perdurará durante todo o ano calendário. E, para seu enquadramento, fazse necessário a análise da receita anual auferida durante o exercício financeiro.

Outro principal critério para caracterização da MPE, conforme dispositivo da legislação específica, é a sua inscrição no Registro de Empresas Mercantis ou no Registro de Pessoas Jurídicas. Além desse registro, o microempreendedor individual, a empresa individual de responsabilidade limitada, as sociedades simples e as sociedades empresárias devem cumprir os requisitos previstos no artigo 17 da mesma Lei Complementar ${ }^{3}$, que contém as hipóteses de restrição para ingresso no programa, como, por exemplo, quando um

$\S 8^{\circ}$ Os membros dos Comitês de que tratam os incisos I e III do caput deste artigo serão designados, respectivamente, pelos Ministros de Estado da Fazenda e do Desenvolvimento, Indústria e Comércio Exterior, mediante indicação dos órgãos e entidades vinculados.

3 Art. 17. Não poderão recolher os impostos e contribuições na forma do Simples Nacional a microempresa ou a empresa de pequeno porte:

I - que explore atividade de prestação cumulativa e contínua de serviços de assessoria creditícia, gestão de crédito, seleção e riscos, administração de contas a pagar e a receber, gerenciamento de ativos (asset management), compras de direitos creditórios resultantes de vendas mercantis a prazo ou de prestação de serviços (factoring);

II - que tenha sócio domiciliado no exterior;

III - de cujo capital participe entidade da administração pública, direta ou indireta, federal, estadual ou municipal;

IV - (REVOGADO);

V - que possua débito com o Instituto Nacional do Seguro Social - INSS, ou com as Fazendas Públicas Federal, Estadual ou Municipal, cuja exigibilidade não esteja suspensa;

VI - que preste serviço de transporte intermunicipal e interestadual de passageiros;

VII - que seja geradora, transmissora, distribuidora ou comercializadora de energia elétrica;

VIII - que exerça atividade de importação ou fabricação de automóveis e motocicletas;

IX - que exerça atividade de importação de combustíveis;

$\mathrm{X}$ - que exerça atividade de produção ou venda no atacado de:

a) cigarros, cigarrilhas, charutos, filtros para cigarros, armas de fogo, munições e pólvoras, explosivos e detonantes;

b) bebidas a seguir descritas:

1 - alcoólicas;

2 - refrigerantes, inclusive águas saborizadas gaseificadas;

3 - preparações compostas, não alcoólicas (extratos concentrados ou sabores concentrados), para elaboração de bebida refrigerante, com capacidade de diluição de até 10 (dez) partes da bebida para cada parte do concentrado;

4 - cervejas sem álcool;

XI - que tenha por finalidade a prestação de serviços decorrentes do exercício de atividade intelectual, de natureza técnica, científica, desportiva, artística ou cultural, que constitua profissão regulamentada ou não, bem como a que preste serviços de instrutor, de corretor, de despachante ou de qualquer tipo de intermediação de negócios;

XII - que realize cessão ou locação de mão-de-obra;

XIII - que realize atividade de consultoria;

XIV - que se dedique ao loteamento e à incorporação de imóveis.

XV - que realize atividade de locação de imóveis próprios, exceto quando se referir a prestação de serviços tributados pelo ISS; ( Redação dada pela Lei Complementar $n^{\circ} 139$, de 10 de novembro de 2011 ) (Produção de efeitos - vide art. $7^{\circ}$ da Lei Complementar $n^{\circ}$ 139, de 2011 )

XVI - com ausência de inscrição ou com irregularidade em cadastro fiscal federal, municipal ou estadual, quando exigível. ( Redação dada pela Lei Complementar n 139, de 10 de novembro de 2011 ) (Produção de efeitos - vide art. $7^{\circ}$ da Lei Complementar $n^{\circ}$ 139, de 2011 )

$\S 1^{\circ}$ As vedações relativas a exercício de atividades previstas no caput deste artigo não se aplicam às pessoas jurídicas que se dediquem exclusivamente às atividades referidas nos $\S \S 5^{\circ}$-B a $5^{\circ}$-E do art. 18 desta Lei Complementar, ou as exerçam em conjunto com outras atividades que não tenham sido objeto de vedação no caput deste artigo.

$\S 2^{\circ}$ Também poderá optar pelo Simples Nacional a microempresa ou empresa de pequeno porte que se dedique à prestação de outros serviços que não tenham sido objeto de vedação expressa neste artigo, desde que não incorra em nenhuma das hipóteses de vedação previstas nesta Lei Complementar.

$\S 3^{\circ}$ (VETADO).

$\S 4^{\circ} \mathrm{Na}$ hipótese do inciso XVI do caput, deverá ser observado, para o MEI, o disposto no art. $4^{\circ}$ desta Lei Complementar. 
dos sócios residirem no exterior, ou, quando a receita bruta anual ultrapassar a prevista na legislação.

Após a habilitação, a empresa tem que manter os mesmos requisitos, sob pena de desenquadramento e consequente perda do benefício.

Logo, o enquadramento no programa representa para o micro e pequeno empresário, diante da sua hipossuficiência, menos encargos e obrigações e mais suporte e apoio, respeitando, assim, o princípio constitucional da igualdade.

Este Regime de Arrecadação Unificado abrange um sistema de desoneração e simplificação, no qual em um único recolhimento mensal incidirá percentual, previsto na legislação, sobre seu faturamento bruto, que engloba o recolhimento do Imposto de Renda da Pessoa Jurídica (IRPJ), do Imposto sobre Produtos Industrializados (IPI), do Imposto sobre Operação e Circulação de Mercadorias e Serviços (ICMS), do Imposto sobre Serviços de Qualquer Natureza (ISS), da Contribuição Social sobre o Lucro Líquido (CSLL), da Contribuição para o Financiamento da Seguridade Social - COFINS, da contribuição para o Programa de Integração Social e Formação do Patrimônio do Servidor Público (PIS/Pasep) e da Contribuição Patronal Previdenciária (CPP).

Traçadas as presentes considerações, passemos a análise da incidência das Contribuições do PIS e da COFINS, no regime monofásico.

\section{DO RECOLHIMENTO DO PIS E DA COFINS}

\subsection{Do recolhimento das contribuições do PIS e da COFINS pelos Optantes do Simples}

A Lei Federal de n ${ }^{\circ} 9.718$ de 27 de novembro de 1998 determina, em seu art. $2^{\text {o }}$, que as contribuições para o PIS/PASEP e para a COFINS, devidas pelas pessoas jurídicas de direito privado, serão calculadas com base no seu faturamento, ou seja, baseadas na Receita Bruta da Pessoa Jurídica.

Somado a isso, a Instrução Normativa da Secretaria da Receita Federal do Brasil SRF de $n^{\circ} 381$, de 30 de dezembro de 2003, dispõe sobre a retenção de tributos e

\footnotetext{
$4 \quad$ Art. $\mathbf{2}^{\mathbf{0}}$ As contribuições para o PIS/PASEP e a COFINS, devidas pelas pessoas jurídicas de direito privado, serão
} calculadas com base no seu faturamento, observadas a legislação vigente e as alterações introduzidas por esta Lei. 
contribuições nos pagamentos efetuados pelas pessoas jurídicas para fornecimento de bens e prestação de serviços, e elenca, em seu art. $1^{\circ}$, quem poderá ter retido na fonte a Contribuição para o Financiamento da Seguridade Social (Cofins) e a Contribuição para o Programa de Integração Social e Formação do Patrimônio do Servidor Público (PIS/PASEP), quais sejam:

I- associações, inclusive entidades sindicais, federações, centrais sindicais e serviços sociais autônomos;

II- sociedades simples, inclusive cooperativas;

III- fundações de direito privado;

IV- condomínios de edifícios.

Ademais, a citada instrução normativa traz, em seu $\S 2^{\circ}$, que as pessoas jurídicas optantes pelo Sistema Integrado de Pagamento de Impostos e Contribuições das Microempresas e das Empresas de Pequeno Porte (Simples) não estão obrigadas a efetuar a retenção a que se refere o caput do art. $1^{\circ}$, ou seja, o PIS e a COFINS.

Desta feita, o recolhimento das contribuições do PIS e da COFINS é feita de forma unificada, deixando, assim, de recolher na etapa anterior, ou seja, a legislação proporciona ao contribuinte optante do simples que o recolhimento ocorra na primeira etapa da cadeia, o que, normalmente, ocorre durante toda a cadeia.

Diante da citada afirmação, tem-se que as contribuições calculadas com base na incidência monofásica ou tributação concentrada também deveria ser aplicada aos optantes do Simples Nacional.

Com isso, os optantes pelo Simples Nacional, desde que importadores e fabricantes de autopeças, medicamentos, perfumaria, cosméticos, dentre outros produtos, quando apresentariam o recolhimento do PIS e da COFINS já incluídas no regime unificado, não deveria realizar um recolhimento adicional, o que será vastamente abordado no capítulo vindouro.

\subsection{Do Princípio da Isonomia Tributária}

Antes de adentrarmos ao regime monofásico, necessário tecer algumas considerações acerca de um dos princípios basiladores do Direito Tributário, qual seja, o Princípio da isonomia ou da igualdade tributária.

Este princípio teve o seu marco inicial quando o Rei João Sem-Terra, em 1215 D.C, assinou a Magna Carta, dando início ao chamado período da monarquia constitucional. Com este ato, originou-se o princípio da legalidade, que preservava os direitos dos burgomestres.

Atualmente, este princípio encontra-se disposto nas Constituições de diversos países e, no Brasil, a isonomia ou igualdade tributária está prevista no Art. 150, II da CF/88, o qual prevê:

Art. 150. Sem prejuízo de outras garantias asseguradas ao contribuinte, é vedado à União, aos Estados, ao Distrito Federal e aos Municípios: 
(omiss)

II - instituir tratamento desigual entre contribuintes que se encontrem em situação equivalente, proibida qualquer distinção em razão de ocupação profissional ou função por eles exercida, independentemente da denominação jurídica dos rendimentos, títulos ou direitos; (grifo nosso)

Essa vedação imposta pelo constituinte, nas palavras de Luciano Amaro, consiste no conjunto de traços que demarcam o campo, o modo, a forma e a intensidade de atuação do poder de tributar ${ }^{5}$

Em relação ao Princípio da Igualdade, pondera sobre o tema Celso Antônio Bandeira de Mello ${ }^{6}$, ao afirmar que:

\footnotetext{
As discriminações são recebidas como compatíveis com a cláusula igualitária apenas e tão-somente quando existe vínculo de correlação lógica entre a peculiaridade diferencial acolhida por residente no objeto, e a desigualdade de tratamento em função dela conferida, desde que tal correlação não seja incompatível com interesses prestigiados na Constituição.
}

Utilizando-se das palavras de Eduardo Sabbag, “o princípio da igualdade tributária é também conhecido por "princípio da proibição dos privilégios odiosos", na medida em que visa coibir a odiosidade tributária, manifestável em comandos normativos discriminatórios, veiculadores de favoritismos por meio de tributação" 7 .

Conclui-se, portanto, que o Princípio da Isonomia Tributária constitui-se do mesmo Princípio da Isonomia posta no art. $5^{\circ}$ da $\mathrm{CF} / 88$, sendo que esta primeira tem uma óbice legislativa, devendo, ainda, ser observada, na sua aplicabilidade, o princípio da capacidade contributiva.

Traçadas as presentes considerações, passemos ao estudo do Regime Monofásico.

\section{DO REGIME MONOFÁSICO}

\subsection{Da incidência monofásica imposta pela Lei $n^{0} 10.147 / 2000$ em relação aos contribuintes optantes do SIMPLES}

\footnotetext{
5 AMARO, Luciano. Direito tributário brasileiro. 9. ed. São Paulo: Saraiva, 2003, p. 107. 
A Lei $n^{\circ} 10.147$, de 21 de dezembro de 2000, dispõe sobre a incidência monofásica das contribuições para o PIS e para a COFINS devidas pelas pessoas jurídicas que procedam à industrialização ou à importação, relacionados na referida Lei, com base na classificação de algumas posições da Tabela de incidência do Imposto sobre Produtos Industrializados (TIPI).

Necessário destacar que a tributação monofásica versa sobre a cobrança do PIS e da COFINS realizada no início da cadeia econômica, ocorrendo, nas fases posteriores, a desoneração dos citados tributos.

Por consequência da tributação ocorrida na origem, com alíquotas majoradas, as operações subsequentes terão as suas alíquotas reduzidas à zero, como, por exemplo, das receitas resultantes da venda de produtos para a higiene pessoal, conforme pode ser verificado na transcrição do art. $1^{\circ}, \mathrm{I}, \mathrm{b}$, da Lei $\mathrm{n}^{\circ}$ 10.147/2000:

\begin{abstract}
Art. $1^{\circ}$ A Contribuição para os Programas de Integração Social e de Formação do Patrimônio do Servidor Público - PIS/PASEP e a Contribuição para o Financiamento da Seguridade Social - COFINS devidas pelas pessoas jurídicas que procedam à industrialização ou à importação dos produtos classificados nas posições 30.01; 30.03, exceto no código 3003.90.56; 30.04, exceto no código 3004.90.46; e 3303.00 a 33.07, exceto na posição 33.06; nos itens 3002.10.1; 3002.10.2; $3002.10 .3 ; 3002.20 .1 ; 3002.20 .2 ; 3006.30 .1$ e 3006.30 .2 ; e nos códigos 3002.90.20; $3002.90 .92 ; 3002.90 .99 ; 3005.10 .10 ; 3006.60 .00 ; 3401.11 .90$, exceto $3401.11 .90 \mathrm{Ex}$ 01; 3401.20.10; e 9603.21.00; todos da Tabela de Incidência do Imposto sobre Produtos Industrializados - TIPI, aprovada pelo Decreto no 7.660, de 23 de dezembro de 2011, serão calculadas, respectivamente, com base nas seguintes alíquotas: (Redação dada pela Lei ${ }^{\circ} 12.839$, de 9 de julho de 2013)

I - incidentes sobre a receita bruta decorrente da venda de: ( Redação dada pela Lei $\mathrm{n}^{\mathrm{o}}$ 10.865, de 2004 ) (Vide art. $3^{\circ}$ da MP n ${ }^{\circ}$ 609, de 8 de março de 2013) (omiss)

b) produtos de perfumaria, de toucador ou de higiene pessoal, classificados nas posições 33.03 a 33.07, exceto na posição 33.06, e nos códigos 3401.11.90, exceto 3401.11.90 Ex 01, 3401.20.10 e 96.03.21.00: 2,2\% (dois inteiros e dois décimos por cento) e 10,3\% (dez inteiros e três décimos por cento); e (Redação dada pela Lei ${ }^{\circ}$ 12.839, de 9 de julho de 2013).
\end{abstract}

Em relação aos contribuintes optantes do SIMPLES, a Lei $\mathrm{n}^{\circ}$ 10.147/2000 vedou, expressamente, em seu art. $2^{\circ}$, parágrafo único, a possibilidade daqueles aplicarem o sistema monofásico:

Art. $2^{\circ}$ São reduzidas a zero as alíquotas da contribuição para o PIS/Pasep e da Cofins incidentes sobre a receita bruta decorrente da venda dos produtos tributados na forma do inciso I do art. $1^{\circ}$, pelas pessoas jurídicas não enquadradas na condição de industrial ou de importador.

Parágrafo único. O disposto neste artigo não se aplica às pessoas jurídicas optantes pelo Sistema Integrado de Pagamento de Impostos e Contribuições das Microempresas e Empresas de Pequeno Porte - Simples. 
Ocorre que, a maioria das vezes, as saídas de produtos efetivadas pelos comerciantes optantes do SIMPLES estavam sofrendo dupla tributação, qual seja: a primeira tributação era realizada na saída (de forma monofásica) e uma nova tributação ocorria dentro do SIMPLES. Essa incongruência será abordada no próximo tópico.

\subsection{Do recolhimento em duplicidade pelas empresas optantes do Simples.}

Conforme afirmado em linhas pretéritas, a Lei $n^{\circ} 10.147 / 2000$ exclui a aplicação de alíquota zero as empresas optantes do SIMPLES. Tal ato importa em inversão das diretrizes constitucionalmente previstas, uma vez que a exclusão acaba por impor uma oneração maior para as empresas que estão submetidas ao regime do SIMPLES.

Em contrapartida, as empresas não optantes pelo regime do SIMPLES, e que pertencem ao mesmo ramo de atividade comercial, contribuem a título de PIS e COFINS de forma diferenciada, ou seja, são menos oneradas do que as microempresas e empresas de pequeno porte, às quais procuraram o Simples com o intuito de usufruir do tratamento diferenciado que a Constituição Federal proporcionou para as citadas empresas.

Ocorre que os princípios constitucionais possuem força normativa suficiente para retirar do ordenamento as normas que possuem incompatibilidade material.

Tais princípios, a exemplo do Princípio da Isonomia, possuem capacidade de concluir que a norma em estudo é plenamente inconstitucional, ao ponto de excluir da redução a zero as alíquotas de PIS e COFINS dos optantes do SIMPLES (parágrafo único do art. $2^{\circ}$ da lei 10.147/00).

Logo, a retromencionada Lei $\mathrm{n}^{\circ}$ 10.147/2000 dispõe sobre a majoração da alíquota em relação aos contribuintes iniciais da circulação econômica (industriais e importadores), de modo a conjugar nessa etapa todo o pagamento que será devido ao longo da circulação do produto.

Quanto aos demais (distribuidores e varejistas), estes possuem alíquota reduzida à zero - sendo esta uma exoneração fiscal apenas superficial, não havendo renúncia alguma de receita pelo Estado.

Como exemplo prático tem-se o presente caso: as alíquotas de PIS e de COFINS imputadas ao importador ou industrial são substancialmente majoradas, correspondendo à aproximada soma das alíquotas que seriam devidas ao longo de toda a cadeia produtiva, e tornando possível, assim, concentrar neste momento a soma do pagamento da COFINS e do 
Paulo Joviniano Alvares dos Prazeres \& Raymundo Juliano Rego Feitosa

PIS/PASEP que seria devido nas sucessivas saídas futuramente perpetradas pelos intermediários, no nosso estudo específico, as farmácias.

Desta feita, a alíquota é majorada vultuosamente para que possa corresponder à soma das alíquotas devidas pelos sucessores da cadeia econômica (varejistas que conduzem a mercadoria até o consumidor), concentrando o pagamento do tributo neste ponto, à idêntica maneira do que se observa nos efeitos simplificadores de arrecadação acarretados pela técnica da substituição tributária.

No entanto, na tributação monofásica ocorre a concentração do momento de recolhimento do tributo referente àquele segmento econômico, com fins de facilitar a fiscalização e a arrecadação. Não há desoneração tributária representada pela redução à zero da alíquota, uma vez que já foi recolhido o tributo no início da cadeia de circulação econômica, para ser então repassado no preço do produto.

Logo, ao proibir a redução a zero das alíquotas de PIS e COFINS insertas no SIMPLES (parágrafo único do art. $2^{\circ}$ da Lei 10.147/00), as empresas optantes terminam por suportar em duplicidade o PIS e a COFINS, contribuindo para a seguridade social com carga superior àquela referente aos não optantes.

É forçoso concluir diante disso que resta indevido o pagamento mensal do percentual referente ao PIS/PASEP e à COFINS feitos "dentro" da alíquota única do Simples, uma vez que a parcela de contribuição a tais títulos já é realizada através dos produtores e importadores, por meio da tributação monofásica.

Diante disso, as empresas optantes do SIMPLES, a exemplo dos farmacêuticos, estão buscando o judiciário com o intuito de sanar tamanha ilegalidade e inconstitucionalidade, conforme será abordado no próximo tópico.

\subsection{Das demandas judiciais realizadas pelas empresas do setor farmacêutico}

Em busca do cumprimento do Princípio da Isonomia Tributária, bem como buscando o benefício concedido pelo constituinte originário aos optantes do SIMPLES, os contribuintes ingressaram com medidas judiciais, buscando pôr fim à inconstitucionalidade trazida pelo ato normativo disposto na Lei No. 10.147/00. 
Merece destacar que a primeira decisão nos Tribunais Superiores que abordou o caso em estudo foi a proferida no julgamento do RESP 1.113.895 do Rio Grande do Norte, abaixo transcrita:

TRIBUTÁRIO. PIS E COFINS. LEI N. 10.147/2000. HOSPITAIS E CLÍNICAS MÉDICAS. ALÍQUOTA ZERO. MEDICAMENTOS UTILIZADOS NA PRESTAÇÃO DO SERVIÇO. INAPLICABILIDADE. 1. Não se aplica a alíquota zero prevista no art. $2^{\circ}$ da Lei n. 10.147/2000 a entidades hospitalares ou clínicas médicas, pois os medicamentos utilizados são insumos para a execução de sua atividade principal, qual seja, prestação de serviços de natureza médico-hospitalar, não tendo na venda de medicamentos, seja no atacado ou no varejo, sua atividade essencial. 2. "As entidades hospitalares e as clinicas médicas não têm como atividade básica a venda de medicamentos no atacado ou no varejo, sendo sua atividade precípua a prestação de serviços de natureza médico-hospitalar a terceiros. Destarte, os medicamentos utilizados pela recorrente são insumos imprescindíveis para o desempenho de suas atividades e, por essa razão, integram o seu custo. Assim, as receitas auferidas em razão do pagamento do serviço pelos seus pacientes englobam o valor dos remédios empregados na prestação do serviço, razão pela qual é descabida a aplicação da alíquota zero" (REsp 1.133.895/RN, Rel. Min. Benedito Gonçalves, Primeira Turma, julgado em 9.3.2010, DJe 17.3.2010). Agravo regimental improvido.

(STJ, Relator: Ministro HUMBERTO MARTINS, Data de Julgamento: 15/03/2011, T2 - SEGUNDA TURMA)

Conforme visto, os senhores ministros entenderam que os medicamentos não são considerados como insumos das clínicas médicas e, por isso, não admitem a tributação monofásica na operação subsequente, subsistindo a restrição imposta pelo Ato Declaratório Interpretativo $n^{\circ} 26 / 2004$.

Ocorre que a Lei $\mathrm{n}^{\circ}$ 10.147/2000 excluiu todas as pessoas jurídicas optantes pelo Simples da aplicação da alíquota-zero, independente da finalidade, inclusive em relação ao ramo farmacêutico, que possui como finalidade a venda de medicamentos.

Como exemplo, vejamos o decurso da ação ajuizada pelo Sindicato do comércio varejista de produtos farmacêuticos do estado do Ceará - SINCOFARMA/CE, onde o TRF da $5^{\text {a }}$ Região deu provimento ao apelo da Fazenda Nacional nos seguintes moldes:

TRIBUTÁRIO. PIS E COFINS. ALÍQUOTA ZERO. VEDAÇÃO DA PESSOA JURÍDICA OPTANTE PELO SIMPLES. PARÁGRAFO ÚNICO DO ART. $2^{\circ}$ DA LEI N ${ }^{\circ} 10.147 / 2000$. CONSTITUCIONALIDADE.

1. A redução a zero das alíquotas do PIS e da COFINS, conforme previsto no art. $2^{\circ}$ da Lei 10.147/2000, para pessoas jurídicas não enquadradas na condição de industrial ou de importador, não se estende para as pessoas jurídicas optantes pelo SIMPLES. Vedação expressa do parágrafo único do art. $2^{\circ}$ da Lei $n^{\circ}$ 10.147/2000.

2. A simples opção pelo SIMPLES constitui regime tributário mais favorável aos contribuintes, de modo que, acaso desejem se submeterem a tal sistemática de tributação, haverão de ter a ciência de que deverão gozar de suas vantagens, bem assim como observar as restrições que lhe são impostas, não sendo lícito a busca dos benefícios de ambos os regimes.

3. Não há razão para se declarar a inconstitucionalidade do parágrafo único do art. $2^{\circ}$ da Lei ${ }^{\circ} 10.147 / 2000$.

4. Apelação e remessa oficial providas. 
Posteriormente, foram interpostos embargos de declaração, em nome do sindicato, mas o citado acórdão não sofreu qualquer alteração:

PROCESSUAL CIVIL - EMBARGOS DECLARATÓRIOS - HIPÓTESES
LEGAIS NÃO PREENCHIDAS (ARTS. 535 USQUE 538 DO CPC) - NÃO
INCIDÊNCIA DO ACÓRDÃO ATACADO EM OMISSÃO, CONTRADIÇÃO OU
OBSCURIDADE - JULGAMENTO DAS QUESTÕES POSTAS EM JUÍZO DE
ACORDO COM O LIVRE CONVENCIMENTO DO MAGISTRADO (ART. 131
DO CPC ) - RECURSO REJEITADO. 1. As hipóteses legais autorizadoras para interposição de Embargos Declaratórios (CPC, arts. 535 usque 538) não foram verificadas, descabendo a utilização de dito recurso para modificação do acórdão regional. Não incidência do acórdão atacado em omissão, contradição ou obscuridade apontadas pela Embargante.

2. Não caracteriza omissão no acórdão recorrido a ausência de menção explícita aos dispositivos legais mencionados, sendo suficiente a apreciação da questão jurídica envolvida, para que tenha havido pleno exame da lide, inclusive para fins de préquestionamento para acesso à instância extraordinária. (Precedentes do STJ).

3. Não está obrigado o Julgador a analisar todos os pontos suscitados pelas partes para formar o livre convencimento, sendo-lhe possível analisar os fatos apresentados, as provas carreadas e utilizar-se da jurisprudência e da legislação aplicável.

4. Os embargos de declaração não se prestam à pretensão de rejulgamento da causa, nem são cabíveis para fins de prequestionamento, na ausência de omissão, obscuridade ou contradição.

5. Embargos Declaratórios rejeitados. Acórdão atacado mantido incólume.

Em contrapartida, a Secretaria da Receita Federal, através de Soluções de Consulta $\mathrm{n}^{\circ} 18$ e 445, da $9^{\mathrm{a}}$ Região Fiscal, que corresponde aos estados do Paraná e Santa Catarina, vem julgando da seguinte forma:

SOLUÇÃO DE CONSULTA No 18 de 18 de Janeiro de 2010

ASSUNTO: Simples Nacional

EMENTA: SIMPLES NACIONAL. MONOFÁSICOS. Para os fatos geradores ocorridos até 31 de dezembro de 2008, na tributação, pelo Simples Nacional, das receitas provenientes da venda de produtos sujeitos à tributação concentrada (i.e., monofásicos), inexistia amparo legal para, de qualquer modo (p.ex., segregação de receitas ou desconsideração de percentuais), alterar os percentuais relativos à Cofins e à Contribuição para o PIS/Pasep. Contudo, para os fatos geradores ocorridos a partir de $1^{\circ}$ de janeiro de 2009 , o Simples Nacional passou a admitir a redução do valor a ser recolhido, nos termos do art. $18, \S 4^{\circ}$, inciso IV, e $\S \S 12$ a 14 , da Lei Complementar $n^{\circ} 123$, de 2006."

SOLUÇÃO DE CONSULTA N ${ }^{\circ} 445$ de 24 de Novembro de 2009 SIMPLES NACIONAL

EMENTA: SIMPLES NACIONAL. MONOFÁSICOS. Para os fatos geradores ocorridos até 31 de dezembro de 2008, na tributação, pelo Simples Nacional, das receitas provenientes da venda de produtos sujeitos à tributação concentrada (i.e., monofásicos), inexistia amparo legal para, de qualquer modo (p.ex., segregação de receitas ou desconsideração de percentuais), alterar os percentuais relativos à Cofins e à Contribuição para o PIS/Pasep. Contudo, para os fatos geradores ocorridos a partir de $1^{\circ}$ de janeiro de 2009, o Simples Nacional passou a admitir a redução do valor a ser recolhido, nos termos do art. $18, \S 4^{\circ}$, inciso IV, e $\S \S 12$ a 14 , da Lei Complementar $\mathrm{n}^{\mathrm{o}} 123$, de 2006. 
Ora, salta aos olhos a total incongruência de posicionamentos existentes entre o órgão administrativo, encarregado de recolher os tributos, e o entendimento dos Tribunais, pois mesmo não havendo previsão na Lei Complementar para as contribuições do PIS e da COFINS na venda de monofásicos, a alíquota prevista para essas contribuições é zero.

Em análise ao artigo 18, $\S 4^{\circ}$, inciso IV, e $\S \S 12$ a 14 da LC 123/2006, pode-se constatar que, a partir do início de 2009, devem os atacadistas e varejistas aplicar a reducão de alíquota do PIS e da COFINS dos valores recolhidos mensalmente, decorrentes dos produtos sujeitos a incidência monofásica, vejamos:

\footnotetext{
Art. 18. O valor devido mensalmente pela microempresa e empresa de pequeno porte comercial, optante pelo Simples Nacional, será determinado mediante aplicação da tabela do Anexo I desta Lei Complementar.

(...)

$\S 4^{\circ} \mathrm{O}$ contribuinte deverá considerar, destacadamente, para fim de pagamento:

IV - as receitas decorrentes da venda de mercadorias sujeitas à substituição tributária e tributação concentrada em uma única etapa (monofásica), bem como, em relação ao ICMS, antecipação tributária com encerramento de tributação;

$\S 12$. Na apuração do montante devido no mês relativo a cada tributo, o contribuinte que apure receitas mencionadas nos incisos IV e $\mathrm{V}$ do $\$ 4^{\circ}$ deste artigo terá direito a reducão do valor a ser recolhido na forma do Simples Nacional calculada nos termos dos $\$ \$ 13$ e 14 deste artigo.

(..)
}

Assim, apesar dos Tribunais terem o entendimento da aplicabilidade da norma disposta na Lei 10.147/00, diante da divergência e da relevância do fato, necessário se faz a atuação do Supremo Tribunal Federal. A matéria em estudo trata-se de caso de interesse geral, cuja decisão não se confina à esfera subjetiva dos direitos exclusivamente dos litigantes do presente processo, mas sim revela útil a grupos inteiros ou uma grande quantidade de pessoas jurídicas.

Logo, a decisão a proferida pelo Pretório Excelso exercerá influência em julgamentos futuros e em curso, bem como poderá editar súmula vinculante sobre o caso em vertente, pois o mesmo apresenta repercussão geral do ponto de vista político e social, na medida em que o recolhimento influencia diretamente nos cofres da União e no balanço contábil das empresas optantes do SIMPLES.

Dito isso, resta demonstrada a necessidade de reconhecimento repercussão geral da matéria, a ser apreciada pelo pleno do STF, nos moldes do art. 543-A, $\S 2^{\circ}$, do CPC:

$\S 1^{\circ}$ Para efeito da repercussão geral, será considerada a existência, ou não, de questões relevantes do ponto de vista econômico, político, social ou jurídico, que ultrapassem os interesses subjetivos da causa. 
Paulo Joviniano Alvares dos Prazeres \& Raymundo Juliano Rego Feitosa

$\S 2^{\circ} \mathrm{O}$ recorrente deverá demonstrar, em preliminar do recurso, para apreciação exclusiva do Supremo Tribunal Federal, a existência da repercussão geral.

Impende ressaltar que, em relação ao ICMS, o STF já se pronunciou sobre a repercussão geral que aborda o tema ICMS, caso análogo à incidência em estudo, conforme pode ser verificado na ementa abaixo colacionada:

EMENTA: CONSTITUCIONAL. TRIBUTÁRIO. ICMS. RESTITUIÇÃO DA DIFERENÇA DO IMPOSTO PAGO A MAIS NO REGIME DE SUBSTITUIÇÃO TRIBUTÁRIA. BASE DE CÁLCULO PRESUMIDA E BASE DE CÁLCULO REAL. ART. 150, $\S 7^{\circ}$, DA CF. ADI 2.675/PE, REL. MIN. CARLOS VELLOSO E ADI 2.777/SP, REL. MIN. CEZAR PELUSO, QUE TRATAM DA MESMA MATÉRIA E CUJO JULGAMENTO JÁ FOI INICIADO PELO PLENÁRIO. EXISTÊNCIA DE REPERCUSSÃO GERAL. (RE 593849 RG, Relator(a): Min. MIN. RICARDO LEWANDOWSKI, julgado em 17/09/2009, DJe-191 DIVULG 08-10-2009 PUBLIC 09-10-2009 EMENT VOL02377-07 PP-01413 LEXSTF v. 31, n. 370, 2009, p. 284-288 LEXSTF v. 31, n. 371, 2009, p. 288-292 )

Conclui-se, portanto, que em relação a presente celeuma, será necessária a manifestação do plenário do STF em julgar os casos apresentados no presente estudo, sob a égide da repercussão geral.

\section{CONSIDERAÇÕES FINAIS}

Aceitar a dupla incidência de PIS e COFINS para as empresas optantes do Simples é retroceder na justiça social. Se a finalidade da criação da Lei Complementar foi desburocratizar e reduzir a carga tributária destes optantes, através de tratamento simplificado e diferenciado, não se pode aceitar a bitributação incidente para as empresas que fazem parte da cadeia que adota o regime monofásico.

Como argumentado ao longo do trabalho, os princípios constitucionais garantem o direito de isonomia tributária e respeitam o limite da capacidade contributiva dos contribuintes. Em consonância com o que foi analisado e com as soluções de consulta expostas, não há qualquer sentido para o MPE, que é o hipossuficiente da cadeia, recolher em duplicidade as contribuições de PIS e COFINS, quando exposto ao regime monofásico.

Assim, nada mais coerente do que a declaração de inconstitucionalidade do disposto no parágrafo único do artigo $2^{\circ}$ da Lei 10.147/2000, em razão da duplicidade de cobrança no 
recolhimento de PIS e COFINS, para as empresas optantes do SIMPLES, que tem tratamento diferenciado assegurado pela Constituição.

Espera-se, assim, que a questão seja levada à Repercussão Geral, com o fito de haver um pronunciamento definitivo, a respeito da matéria, que é tão relevante para os micro e pequenos empresários, que são responsáveis por um dos pilares de sustentação da economia brasileira.

\section{REFERÊNCIAS}

AMARO, Luciano. Direito tributário brasileiro. 9. ed. São Paulo: Saraiva, 2003.

BANDEIRA DE MELLO, Celso Antônio. O conteúdo do princípio da igualdade. São Paulo: Malheiros, 1999.

Constituição da República Federativa do Brasil de 1988. Disponível em: http://www.planalto.gov.br/ccivil_03/constituicao/constitui\%C3\%A7ao.htm, acesso: 10 de fevereiro de 2019.

Instrução Normativa 381 de 30 de dezembro de 2003. Que dispõe sobre a retenção de tributos e contribuições nos pagamentos efetuados pelas pessoas jurídicas que menciona a outras pessoas jurídicas pelo fornecimento de bens e pela prestação de serviços. Disponível em: http://www.receita.fazenda.gov.br/legislacao/ins/2003/in3812003.htm, acesso em 10 de fevereiro de 2019.

Lei Complementar 123 de 14 de dezembro de 2006. Que Institui o Estatuto Nacional da Microempresa e da Empresa de Pequeno Porte; altera dispositivos das Leis no ${ }^{\circ}$ s.212 e 8.213, ambas de 24 de julho de 1991, da Consolidação das Leis do Trabalho - CLT, aprovada pelo Decreto-Lei $n^{\circ} 5.452$, de $1^{\circ}$ de maio de 1943, daLei $n^{\circ} 10.189$, de 14 de fevereiro de 2001 , da Lei Complementar $\mathrm{n}^{\circ}$ 63, de 11 de janeiro de 1990; e revoga as Leis $n^{\circ} \mathrm{s} 9.317$, de 5 de dezembro de 1996, e 9.841, de 5 de outubro de 1999. Alterada pela Lei Complementar $\mathrm{n}^{\circ}$ 127, de 14 de agosto de 2007. Alterada pela Lei Complementar $\mathrm{n}^{\mathrm{o}}$ 128, de 19 de dezembro de 2008 . Republicação em atendimento ao disposto no art. $6^{\circ}$ da Lei Complementar $n^{\circ} 128$, de 19 de 
Paulo Joviniano Alvares dos Prazeres \& Raymundo Juliano Rego Feitosa

dezembro de 2008 . Alterada pela Lei Complementar $\mathrm{n}^{\circ}$ 133, de 28 de dezembro de 2009 . Alterada pela Lei Complementar $\mathrm{n}^{\mathrm{o}}$ 139, de 10 de novembro de 2011. Republicação em atendimento ao disposto no art. $5^{\circ}$ da Lei Complementar $n^{\circ} 139$, de 10 de novembro de 2011 . Alterada pela Lei $\mathrm{n}^{\circ}$ 12.792, de 28 de março de 2013. Diponível em: http://www.receita.fazenda.gov.br/Legislacao/LeisComplementares/2006/leicp123.htm, acesso em 10 de fevereiro de 2019.

Lei 10.147 de 21 de dezembro 2000. Que dispõe sobre a incidência da contribuição para os Programas de Integração Social e de Formação do Patrimônio do Servidor Público PIS/Pasep, e da Contribuição para o Financiamento da Seguridade Social - Cofins, nas operações de venda dos produtos que especifica. Disponível em: http://www.receita.fazenda.gov.br/Legislacao/leis/Ant2001/lei1014700.htm, acesso em 10 de fevereiro de 2019.

Lei 9718 de 27 de novembro 1998. Que altera a legislação tributária. Disponível em: http://www.receita.fazenda.gov.br/Legislacao/leis/Ant2001/lei1014700.htm, acesso em 10 de fevereiro de 2019.

SABBAG, Eduardo. Manual de direito tributário. 4ª Edição. São Paulo: Saraiva, 2012.

Soluções de consulta da Secretaria da Receita Federal do Brasil. Disponível em: http://decisoes.fazenda.gov.br/netahtml/decisoes/decw/pesquisaSOL.htm. acesso em 11 de fevereiro de 2019. 